\title{
Priority setting for research in the field of medical ethics in the Islamic Republic of Iran: a Delphi study
}

\author{
Mahshad Noroozi, ${ }^{1}$ Bagher Larijani, ${ }^{1,2}$ Saharnaz Nedjat, ${ }^{3}$ Kiarash Aramesh ${ }^{4,5}$ and Pooneh Salari ${ }^{1}$
}

${ }^{1}$ Medical Ethics and History of Medicine Research Center; ${ }^{2}$ Endocrinology and Metabolism Research Center, Endocrinology and Metabolism Clinical Sciences Institute; ${ }^{3}$ Department of Epidemiology and Biostatistics, Tehran University of Medical Sciences, Tehran, Islamic Republic of Iran. (Correspondence to: Pooneh Salari: poonehsalari@gmail.com). ${ }^{4}$ The James F. Drane Bioethics Institute, Edinboro University of Pennsylvania, United States of America; ${ }^{5}$ Department of Biology and Health Sciences, College of Science and Health Professions, Edinboro University of Pennsylvania, United States of America.

\begin{abstract}
Background: Priority-setting is one way to develop research in a particular field.

Aims: We aimed to identify and prioritize the most important medical ethics issues for research in the Islamic Republic of Iran.

Methods: A 3-round Delphi survey was conducted using a questionnaire covering 77 medical ethics topics in 10 categories and subcategories (extracted from literature review); this was emailed to 40 experts in medical ethics. The participants rated categories and subcategories for importance on a 5-point Likert scale and ranked the topics based on their research priorities. The highest Likert score showed the most important issue and the lowest priority score indicated the first priority.

Results: After consensus, the panel identified 6 categories as the highest priority and most important areas: professionalism [priority score $=2.66$, standard deviation $(\mathrm{SD}) 2.63$, importance score $=4.45, \mathrm{SD} 0.72$ ], education (priority score $=$ 3.12, SD 1.89, importance score $=4.25, \mathrm{SD} 0.84$ ), end of life (priority score $=3.79, \mathrm{SD} 1.91$, importance score $=4.47, \mathrm{SD} 0.66$ ), beginning of life (priority $=4.62, \mathrm{SD} 1.68$, importance score $=4.26, \mathrm{SD} 0.61$ ), public health (priority score $=5.20, \mathrm{SD} 2.39$, importance score $=4.29, \mathrm{SD} 0.75$ ), and ethics in research (priority score $=5.33, \mathrm{SD} 1.97$, importance score $=4.34, \mathrm{SD} 0.64$ ).
\end{abstract}

Conclusion: The rankings for priority and importance was not the same. Our results highlight a lack of applicable knowledge in the areas of professionalism and end of life. This study could be used as a foundation for developing further investigations by ensuring the most appropriate use of limited resources.

Keywords: priority setting, research, medical ethics, Islamic Republic of Iran

Citation: Noroozi M; Larijani B; Nedjat S; Aramesh K; Salari P. Priority setting for research in the field of medical ethics in the Islamic Republic of Iran: a Delphi study. East Mediterr Health J. 2020;26(5):531-538. https://doi.org/10.26719/emhj.19.085

Received: 26/12/17; accepted: 23/08/18

Copyright (C) World Health Organization (WHO) 2020. Open Access. Some rights reserved. This work is available under the CC BY-NC-SA 3.0 IGO license (https://creativecommons.org/licenses/by-nc-sa/3.o/igo).

\section{Introduction}

Modern health care systems are confronting new ethical challenges along with global medical developments, which highlights the need for more investigations.

Apart from universal moral standards, any society's culture, religion and behaviour patterns have major impacts on ethical norms (1) and bring different necessities. Medical ethics has a long history in the Islamic Republic of Iran, going back to the Zoroastrianism era, in association with the worthy influences of the Muslim scientists $(2,3)$. However, modern developments in medical ethics started in 2002 via the medical ethics strategic plan of the Academy of Medical Sciences $(4,5)$ : insisting on high quality research, 2 of the 6 strategies for research development in medical ethics are "foundation of needs assessment studies and prioritizing research in medical ethics" and "supporting high-priority research projects" (6). Those goals reflect the importance of research in medical ethics; limited resources mean that prioritizing research activities is extremely important.

After operationalizing the strategic plan in 2002, scientific production increased as exemplified by the number of articles published during 1990-2014 by
Tehran University of Medical Sciences (315), Shahid Beheshti University of Medical Sciences (126) and Shiraz University of Medical Sciences (58) (7).

From another standpoint, in order to support professional development and the advancement of research, designing a research road map for medical ethics activities is required. Road mapping is a consensual process which identifies the best way to proceed (8). It provides step-by-step direction to achieve the specific research objectives, explaining the ideal situation, and helping medical ethicists to identify the gap between recent developments and requirements $(9,10)$. Prioritizing research areas is the primary step for road mapping (10); it identifies a clear strategy for future investigations by addressing specific research questions and changing priorities (11).

Moreover, the limited financial and human resources are more pressing in developing countries and have major impact in research planning (11). Thus, interventions should arise from valid prioritization of problem.

In the Islamic Republic of Iran, limited studies have been conducted to identify the most important and prioritized medical ethics topics (12); none were 
conclusive. Further, those studies did not concentrate on the views of ethicists on ethical issues in a particular heath care context did they seek the opinion of clinical bioethicists. In order to determine the research road map, we aimed at identifying the most prioritized and important issues in medical ethics to be further investigated.

\section{Methods}

\section{Study design}

A 3-round Delphi study was conducted to identify and prioritize the most important medical ethics issues for research. The study was performed in the Medical Ethics and History of Medicine Research Center of Tehran University of Medical Sciences from October 2015 until April 2016. We used the Delphi method to achieve experts' consensus on specific issues and make the prioritization process possible (13), to increase forecast accuracy and to achieve accurate estimation by experts' opinions in a particular field (14). Experts having sufficient clinical and ethical expertise were selected from various parts of the health system as a nominal group who consented verbally and communicated via email. To maximize reliability, the same participants were chosen for all 3 rounds. Two of the authors working independently checked the responses and clarified the themes. Credibility was assured by providing explicit descriptions of the issues and the decision-making process.

\section{Round 1: Identifying medical ethics research topics}

In the first round, we reviewed the most relevant literature and resources, including books, encyclopaedias and articles; then the most relevant research topics were extracted. The Delphi questionnaire was designed by 2 of the authors; it consisted of 77 topics divided into 10 categories and subcategories.

The questionnaire, along with a letter explaining the aim of the study, was emailed to 40 experts in medical ethics. The experts were asked to give their opinion about our categorization and add other topics if they thought we had missed any. Email reminders were sent to nonresponders after 4 weeks.

Then, the categories were revised based on the received feedback. They were collated through a process of discussion to achieve agreement by 2 researchers.

\section{Round 2: Determination of priority and importance}

The data obtained from the first round were incorporated into a new questionnaire to determine the importance and priority of the 10 categories and the subcategories. The participants were asked to rate categories and subcategories on a 5-point Likert scale ( $1=$ least important; 5 = most important) according to their perceptions of the level of importance. They were also asked to identify the research priority of the topics $(1=$ highest priority and 5 $=$ lowest priority).

\section{Round 3: Reaching consensus}

In the third round, the questionnaire was emailed to participants who responded to the first 2 rounds. The participants received the descriptive statistics (means) for categories and subcategories. To reach consensus, the participants were allowed to reflect on the scores and to rate the importance and priority of each category and subcategory again.

Data were analysed using SPSS, version 23. Descriptive statistics [mean and standard deviation (SD)] were used to evaluate consensus agreement for level of importance and priority. To ensure external validity, a minimum response rate of $50 \%$ was considered.

\section{Ethical considerations:}

This study was part of a PhD dissertation in medical ethics. The research ethics committee of Tehran University of Medical Sciences approved the project. Participation was voluntary. The participants' identity remained anonymous to other members. Informed consent was assumed by the return of the questionnaire.

\section{Results}

\section{Round 1}

Demographic characteristics of the panel members are presented in Table 1. Thirty four participants of the 40 who were originally selected ( $85 \%$ response rate) returned the questionnaire; the number of relevant research topics was raised to 95. Any duplication was eliminated and the questionnaire was finalized. All 10 categories and their subcategories are itemized in Figure 1.

\begin{tabular}{lccc}
\hline Table 1 Demographic characteristics of the panel members & & & \\
Variable & Round 1 & Round 2 & Round $\mathbf{3}$ \\
No. (\%) participants & $34(85.0)$ & $31(77.5)$ & $25(62.5)$ \\
Sex (No. female/male) & $17 / 17$ & $15 / 16$ & $13 / 12$ \\
Level of higher education (No.) & 26 & 25 & 21 \\
Doctoral degree & 1 & 1 & - \\
Master's degree & 5 & 4 & 3 \\
Specialty degree & 2 & 1 & 1 \\
Doctoral \& specialty degree & & \\
\hline
\end{tabular}









\section{Round 2}

Thirty-one (77.5\%) panel members returned the questionnaire.

In this round, professionalism (mean priority score $=$ 3.75, SD 2.60, mean importance score $\pm=4.63, \mathrm{SD} 0.61$ ), education (mean priority score $=3.93$, SD 2.49 , mean importance score $=4.53, \mathrm{SD} 0.63$ ), end of life (mean priority score $=4.27, \mathrm{SD} 2.08$, mean importance score $=$ 4.55, SD 0.57), the beginning of life (mean priority score $=4.37, \mathrm{SD} .36$, mean importance score $=4.44, \mathrm{SD}$ 0.63), ethics in research (mean priority score $=4.68, \mathrm{SD} 2.23$, mean importance score $=4.33, \mathrm{SD} 0.60$ ), theoretical underpinning of medical ethics (mean priority score $=$ 5.20, SD 3.10, mean importance score $=4.14$, SD 0.70), and public health (mean priority score $=5.51, \mathrm{SD} 2.51$, mean importance score $=4.44, \mathrm{SD} 0.63$ ) gained the highest priority scores.

The categories ranked as the least priority included vulnerable groups, biotechnology, and environmental issues in medical ethics.

The top 10 priority subcategories in all groups were physician-patient relationship, ethics in teaching/ learning medicine, withholding/withdrawing treatment, termination of pregnancy, informed consent in research, religious medical ethics, and policy-making.

\section{Round 3}

Twenty-five (62.5\%) panel members completed the third round. The panel identified 6 categories as the highest priority areas: professionalism, education, end of life, beginning of life, public health, and ethics in research (Table 2).

Informed consent in research (mean importance score $=4.80, \mathrm{SD} 0.40$ ), policy-making (mean importance score $=4.69, \mathrm{SD}$ 0.47), and the physician-patient relationship (mean importance score $=4.68, \mathrm{SD}$ 0.55) were the most important subcategories (Table 2).

\section{Discussion}

In this Delphi study consensus opinion ranked professionalism as the highest priority. Although research priorities indicate genuine ethical concerns, there are a few surprises in our findings. The 6 topics ranked as highest priority also gained the highest importance scores, however their order was not the same. This Delphi consensus rated the most important category as end of life. It is interesting that the panel experts prioritized the topics by considering the importance of this issue. For instance, the end of life issue was the most important one in medical ethics while panel experts preferred more research on professionalism, and so on.

Bagheri surveyed Iranian medical ethics priorities in 2011 and reported patient rights, the physicianpatient relationship, informed consent and the financial relationship between physician and patient among the top 10 priorities (12). Since these topics are categorized under the theme of professionalism, it seems that our study is in line with the Bagheri study, although the methods used were different.

In another study, Bagheri introduced the top 10 bioethical challenges in Islamic countries in which Muslim bioethicists ranked "the relationship between law, ethics, and fatwa", "human rights" and "Islamic principles of bioethics" as 1st, 2nd and 8th respectively (15), whereas we considered these topics as subcategories of "theoretical underpinning of medical ethics", which was rated as the 7th priority in our study. This difference in ranking shows that Iranian ethicists are emphasizing more on practical issues than theoretical ones.

The priorities and importance identified by panel members will affect patients in different ways and to varying degrees because identifying and resolving ethical problems can improve the quality of health care delivery (16). The effect size of each issue on the intended field is also important in priority setting. Professionalism and its most important subcategory, the physician-

\begin{tabular}{|c|c|c|c|c|c|}
\hline \multirow[t]{3}{*}{ Issue } & \multicolumn{4}{|c|}{ Round 3 score $^{\mathrm{a}}$} & \multirow[t]{3}{*}{ High priority subgroup } \\
\hline & \multicolumn{2}{|c|}{ Priority } & \multicolumn{2}{|c|}{ Importance } & \\
\hline & Mean & SD & Mean & SD & \\
\hline Professionalism & 2.66 & 2.63 & 4.45 & 0.72 & Physician-patient relationship \\
\hline Education & 3.12 & 1.89 & 4.25 & 0.84 & Ethics in teaching/learning medicine \\
\hline End of life & 3.79 & 1.91 & 4.47 & 0.66 & Withholding \& withdrawing treatment \\
\hline Beginning of life & 4.62 & 1.68 & 4.26 & 0.61 & Termination of pregnancy \\
\hline Public health & 5.20 & 2.39 & 4.29 & 0.75 & Policy-making \\
\hline Ethics in research & 5.33 & 1.97 & 4.34 & 0.64 & Informed consent \\
\hline Vulnerable & 6.25 & 2.30 & 4.04 & 0.69 & Children \& adolescence \\
\hline Theoretical underpinning of medical ethics & 6.50 & 3.02 & 4.04 & 0.70 & Religious medical ethics \\
\hline Biotechnology & 8.66 & 0.96 & 3.41 & 0.92 & Genetics \\
\hline Environmental issues in medical ethics & 9.29 & 0.99 & 3.27 & 0.98 & Genetics \& environmental human health \\
\hline
\end{tabular}

$\mathrm{SD}=$ standard deviation.

${ }^{a}$ For priority, the lower the score, the greater the priority; for importance, the higher the score, the greater the importance. 
patient relationship, have a major impact on patient care. The most interesting result of this study is ranking professionalism and the physician-patient relationship as the highest priority: this also receives much attention in the media and at the level of government. For instance the "Professionalism enhancement package" for making evolution in education of medical sciences, establishment of "Professionalism offices" in medical universities, inclusion of professionalism in the medical ethics course for undergraduates, and holding seminars and congresses on professionalism (all of which necessitates research and education through the issue) demonstrate the great emphasis on professionalism. Furthermore, to solve the challenges of professionalism, we should approach these via the physician-patient relationship as the main problem and the most prevalent reason for medical complaints in our country (17). Today, professionalism has a central role in patient care, is considered as a competency and has shifted from a conceptual domain to one of the 6 main medical education competencies $(18,19)$. Ziring et al. advocate long-term studies for the identification and remediation of professionalism in medical students (20).

Our approach to medical education as the 2nd priority has 2 dimensions: ethics in medical education and teaching medical ethics. Amini et al. highlighted professionalism and ethics as the 4th research priority in medical education in the Eastern Mediterranean Region (21). Rhodes and Cohen believe that both concepts of medical ethics should be considered in designing medical education (22). Nabeiei et al. reported medical ethics and professionalism as the first priority in medical education in the Iranian context, and for professors' education, medical ethics was the highest priority subcategory (23).

Students first encounter medical ethics concepts when confronting role models' (medical teacher) behaviour (informal education) and its role in medical education is undeniable. Ethics education enables both medical students and professionals to understand ethical principles and to recognize ethical considerations in practice. Therefore, we should empower medical education, specifically professionalism and ethics education, in parallel with other needs of medical students at different levels. Madani et al. recommended virtue-centred education and education on controlling moral emotions to facilitate ethical internalization and teaching ethical practices (24). It is of note that current medical students will have a significant role in training the next generation of physicians, thus teaching ethical principles to medical students and considering ethical observations in teaching has long-term benefits in health care delivery systems and public health.

The 3rd priority was end of life, although the Islamic bioethicists did not give priority to end of life (15). Accordingly, death indicators and length of time that efforts should be continued to sustain life should be defined (25). Religious beliefs, social situation, cultural considerations and professional attitudes impact on medical practice and professionals' ethical sensitivity $(26,27)$, especially since Iranian Islamic law has a pivotal role on end of life decision-making and its ethical considerations.

As specified in Islamic teachings, human life does not belong to the person and should be preserved as much as possible. Mobasher et al. showed that in Islamic society (in the Shiite perspective), decision-making for the end of life is an important issue, and patient autonomy cannot be considered as the basis for it (25).

The category "beginning of life" was rated as the 4th priority. For ethical decision-making at the beginning of life and termination of pregnancy, the definition of human life and the time when human life begins should be determined to define the moral status of the human embryo and its rights as a human being (28). In the Islamic view, ensoulment as a religious concept shapes our moral judgment about beginning of life issues. Although termination of pregnancy is forbidden after ensoulment in all schools of Islamic jurisprudence, it is allowed before ensoulment under certain circumstances (28). Based on the views of the Shiite authorities (fatwas), the Therapeutic Abortion Act was approved in May 2005 by the Iranian parliament. It seems that we will require ethical studies focusing on all aspects of this issue and on identifying the indications for termination.

Contrasting with our study, assisted reproductive technology (ART) did not get priority in the Bagheri study (15). Further, ART, especially third party reproduction techniques, raises several ethical considerations (29) that need to be answered. The concept of kinship is different in different religious and cultural contexts, and its definition has legal, ethical and religious consequences which affects motherhood, marriage and inheritance for couples who use ART (29). Among the Muslim Middle Eastern countries, only in the Islamic Republic of Iran and Lebanon is the use of third party assisted reproductive techniques permitted (30).

Earlier, the primary focus of medical ethics was on patients' rights and the physician-patient relationship; currently the international policies give more emphasis to public health (31), and the emergence of new ethical challenges makes this area more attractive and more prominent (32). In public health, the whole community is regarded as a patient, and health care services should be provided based on public interest (33). Equity in access to resources was ranked as the 2 nd highest ethical challenge of the public health care system in a study from Saudi Arabia (34). This point may explain why our participants rated public health as the 5th highest priority for more studies.

Medicine requires scientific investigation for the development of knowledge and technologies. After the events of World War II and the Nazi experiments, the world was sensitive to ethics in biomedical research: efforts were made to comply with and implement codes of research ethics, and to obligate researchers to respect the codes. 
In the late 1990s, the number of biomedical research studies increased in the Islamic Republic of Iran; this growth raised ethical concerns in the field of research. Therefore, the national codes of research ethics were compiled and national and organizational research ethics committees established (35). The paternalism paradigm shifted after the establishment of the regulatory system (35); new issues were raised necessitating more investigations.

Theoretically, the basic principles of bioethics have been discussed for years by Iranian scholars and still there is open debate. Although biotechnological development and environmental issues are extremely important and the related challenges are rapidly changing, we need to focus more on basic practical issues. Additionally, the results of any such study may change dramatically within a few years.

The main limitation of our study is its (non) generalizability outside the country because our participants were probably influenced by the dominant atmosphere of the health system. However we predict that professionalism will be ranked as one of the most prioritized issues.

In addition, as our participants were clinical and ethical experts, the results may not be representative of the health system as a whole. One of the strengths of our study was the lack of face to face encounters and interrelationships during consensus. So there is the hope that we reached genuine consensus.
Focusing on the top priorities helps us to highlight the research road map of medical ethics in showing new directions to knowledge and refocusing new investigations.

\section{Conclusion}

Emphasizing the priorities for further investigations in medical ethics highlights the lack of proper knowledge in those areas. The results of this study may indicate poor dissemination of information due to improper publication of studies, lack of attentiveness to research information, poor methodology, and lack of proper perception of the published information because of aberrant interpretation of research data. Although we do not claim the resulting list of research priorities to be perfect, it is assumed that it could provide useful information for initiating more investigations. In order to make this study more meaningful and applicable, we have to use this study as a basis for identifying an action plan and designing a road map for future research; doing this will create a foundation for developing more investigations by ensuring the most appropriate use of limited resources. This will persuade the profession to construct research collaborations in priority domains.

Funding: This study was part of a PhD dissertation in medical ethics. The School of Medicine of Tehran University of Medical Sciences supported the study financially.

Competing interests: None declared.

\section{Détermination des priorités pour la recherche dans le domaine de l'éthique médicale en République islamique d'Iran : étude selon la méthode de Delphes}

\section{Résumé}

Contexte : La détermination des priorités constitue l'une des façons pour développer la recherche dans un domaine particulier.

Objectifs : La présente étude visait à identifier et à hiérarchiser les questions d'éthique médicale les plus importantes pour la recherche en République islamique d'Iran.

Méthodes : Une étude à trois séries d'interrogations selon la méthode de Delphes a été menée en utilisant un questionnaire couvrant 77 thèmes liés à l'éthique médicale dans dix catégories et sous-catégories (extraites d'une revue de la littérature). Ce questionnaire a ensuite été envoyé par courrier électronique à 40 experts de l'éthique médicale. Les participants ont évalué l'importance des catégories et sous-catégories selon une échelle de Likert à cinq points et ont classé les thèmes en fonction de leurs priorités de recherche. Le score le plus élevé sur l'échelle de Likert indiquait la question la plus importante, et le score de priorité le moins élevé indiquait la première priorité.

Résultats : Après consensus, le panel a identifié six catégories comme prioritaires et les domaines les plus importants : le professionnalisme [score de priorité $=2,66$, écart type (E.T.) 2,63, score d'importance $=4,45$, E.T. 0,72], l'éducation (score de priorité $=3,12$, E.T. 1,89 , score d'importance $=4,25$, E.T. 0,84), la fin de vie (score de priorité $=3,79$, E.T. 1,91 , score d'importance $=4,47$, E.T. 0,66), le début de vie (score de priorité $=4,62$, E.T. 1,68, score d'importance = 4,26, E.T 0,61), la santé publique (score de priorité $=5,20$, E.T. 2,39, score d'importance $=4,29$, E.T. 0,75$)$ et l'éthique de la recherche (score de priorité $=5,33$, E.T. 1,97, score d'importance $=4,34$, E.T. 0,64).

Conclusion : Les classements par ordre de priorité et d'importance étaient différents. Nos résultats mettent en lumière un manque de connaissances applicables dans les domaines du professionnalisme et de la fin de vie. Cette étude pourrait servir de base pour mettre au point des recherches plus poussées en garantissant l'utilisation la plus appropriée de ressources limitées. 


$$
\text { ترتيب أولويات البحوث في بحال الأخلاقيات الطبية في جمهورية إيران الإسلامية: دراسة باستخدام أسلوب دلفي }
$$

$$
\text { الخلفية: يعد ترتيب الأولويات أحد أساليب تطوير البحوث في ججال ما. }
$$

الأهداف: هدفت الدراسة إلى تحديد أهم المسائل المتعلقة بالأخلاقيات الطبية وترتيب أولوياتها لأغر اض بحثية في جمهورية إيران الإسلامية.

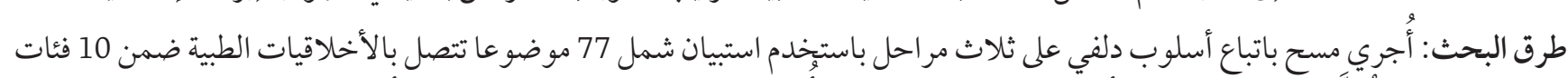

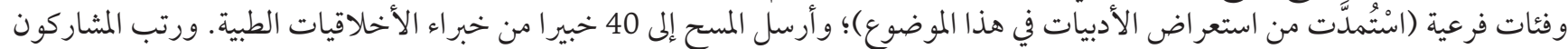

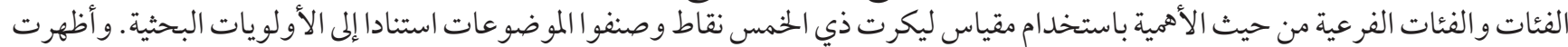

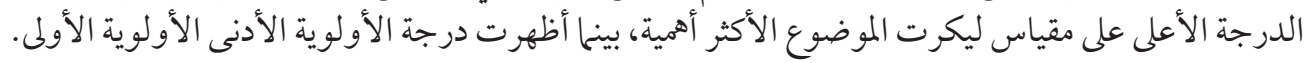

النتائج: بعد التوصل إلى توافق في الآراء، حدد فريق الخبراء 6 فئات تمثل الأولوية الأولى والموضوعات الأكثر أهمية، وهي: الاحتراف افت المهني

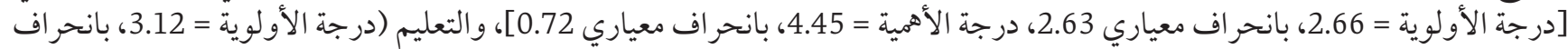

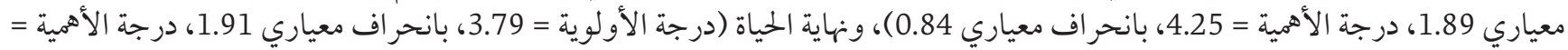

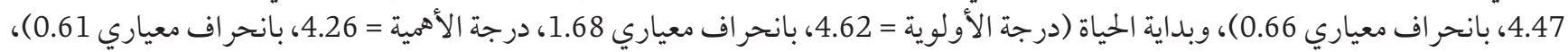

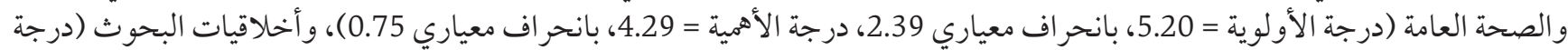

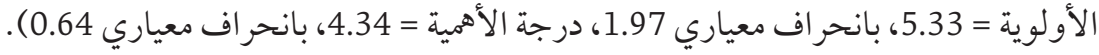
الاستنتاج: لم يكن هناك تطابق في تصنيفات الأولوية والأهمية. وتبرز النتائج التي توصل لها الباحثون غياب المعرفة التطبيقية في بجالات الاحتراف

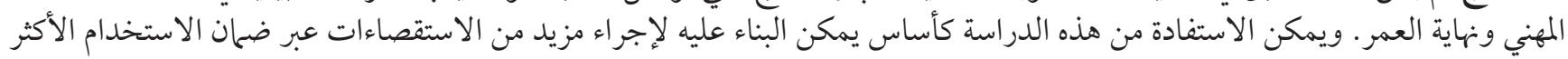
ملاعمة للموارد المحدودة.

\section{References}

1. Drane J. Medicine and the possibility of a universal ethics. Santiago: Universidad de Chile, Centro Interdisciplinario de Estudios en Bioética; 2000 (http://www.uchile.cl/portal/investigacion/centro-interdisciplinario-de-estudios-en-bioetica/publicaciones/76984/medicine-and-the-possibility-of-a-universal-ethics, accessed 20 September 2019).

2. Larijani B, Zahedi F. Contemporary medical ethics: an overview from Iran. Dev World Bioeth. 2008;8(3):192-6. doi:10.1111/j.14718847.2006.00180.x

3. Larijani B, Zahedi F, Emami Razavi SH. [Medical ethics history in Iran]. Iran J Diabet Metabolism. 2006;6(2):113-24. [in Farsi].

4. Larijani B, Malek-Afzali H, Zahedi F, Motevaseli E. Strengthening medical ethics by strategic planning in the Islamic Republic of Iran. Dev World Bioeth. 2006;6(2):106-10. doi:10.1111/j.1471-8847.2006.00145.X

5. Zahedi F, Emami Razavi SH, Larijani B. A two-decade review of medical ethics in Iran. Iranian J Publ Health. 2009;38(1):40-6.

6. Anonymous. [The Second National Strategic Plan for Medical Ethics in the Islamic Republic of Iran]. Tehran: Ministry of Health and Medical Education; 2017. [in Farsi]

7. Zahedi F, Zahedi R, Hematian F, Larijani B. Scientific products of Iranian researchers in the field of medical ethics during 1990 to 2014. Proceedings of the 4th Annual Congress of Medical Ethics, 2016. Tehran: Tehran University of Medical Sciences; 2016.

8. Ma T, Liu S, Nakamori Y. Roadmapping as a way of knowledge management for supporting scientific research in academia. Syst Res. 2006;23:743-55. doi:10.1002/sres.708

9. Salo A, Cuhls K. Technology foresight-past and future. J Forecast. 2003;22:79-82. doi:10.1002/for.846

10. McGregor S, Henderson KJ, Kaldor JM. How are health research priorities set in low and middle income countries? A systematic review of published reports. PLoS ONE. 2014;9(10):e108787. doi:10.1371/journal.pone.0108787

11. Chalmers I, Glasziou P. Avoidable waste in the production and reporting of research evidence. Lancet. 2009;374(9683):86-9. doi:10.1016/So140-6736(09)60329-9

12. Bagheri A. [Iranian medical ethics priorities: the results of a national study]. Iran J Med Ethics Hist Med. 2011;4(5):39-48. [in Farsi]

13. Moreno-Casbas T, Martín-Arribas C, Orts-Cortés I, Comet-Cortés P. Identification of priorities for nursing research in Spain: a Delphi study. J Adv Nurs. 2001;35(6):857-63. doi:10.1046/j.1365-2648.2001.01923.x

14. McMillan SS, King M, Tully MP. How to use the nominal group and Delphi techniques. Int J Clin Pharm. 2016;38(3):655-62. doi:10.1007/s11096-016-0257-X

15. Bagheri A. Priority setting in Islamic bioethics: top 10 bioethical challenges in Islamic countries. Asian Bioethics Rev. 2014;6(4):391-401. 
16. Fleurence RL, Torgerson DJ. Setting priorities for research. Health Policy. 2004;69(1):1-10. PMID:15484602

17. Jafarian A, Parsapoor A, Hajtarkhani A, Asghari F, Imami Razavi S H, Yalda A. [A survey on the complaints registered in medical council organization of Tehran]. Iran J Med Ethics Hist Med. 2009;2:67-74. [in Farsi]

18. Braddock $\mathrm{CH}$ 3rd, Eckstrom E, Haidet $\mathrm{P}$. The new revolution in medical education: fostering professionalism and patient-centered communication in the contemporary environment. J Gen Intern Med. 2004;19 (5 Pt 2):610-11. doi:10.1111/j.15251497.2004.45003.X

19. Batalden P, Leach D, Swing S, Dreufus S. General competencies and accreditation in graduate medical education. Health Aff. 2002;21:103-11. PMID:12224871

20. Ziring D, Danoff D, Grosseman S, Langer D, Esposito A, Jan MK, et al. How do medical schools identify and remediate professionalism lapses in medical students? A study of U.S. and Canadian medical schools. Acad Med. 2015;90:913-20. doi:10.1097/ ACM.0000000000000737

21. Amini M, Kojuri J, Lotfi F, Karimian Z, Abadi AS. Research priorities in medical education in the Eastern Mediterranean Region. East Mediterr Health J. 2012;18(7):687-92. PMID:22891514

22. Rhodes R, Cohen DS. Understanding, being, and doing medical ethics in medical education. Camb Quart Healthcare Ethics. 2003;12(1):39-53. PMID:1262520

23. Nabeiei P, Amini M, Ghanavati S, Marhamati S. Research priorities in medical education at Shiraz University of Medical Sciences: categories and subcategories in the Iranian context. J Adv Med Educ Professionalism. 2016;4(1):26-32. PMID:26793723

24. Madani M, Larijani B, Madani E, Ghasemzadeh N. Establishment of medical education upon internalization of virtue ethics: bridging the gap between theory and practice. J Med Ethics Hist Med. 2017;10:3.

25. Mobasher M, Aramesh K, Zahedi F, Nakhaee N, Tahmasebi M, Larijani B. End-of-life care ethical decision-making: Shiite scholars' views. J Med Ethics Hist Med. 2014;7:2.

26. Jarallah J. Islamic medical ethics: how different? JTU Med Sci. 2008;3(1):61-3.

27. Larijani B, Motevasseli E. Needs and necessities of medical ethics education. J Med Ethics Hist Med. 2006;0(Suppl. 1):21-7.

28. Aramesh k. Abortion: an Islamic ethical view. Iran J Allergy Asthma Immunol. 2007;6(Suppl. 5):29-33.

29. Larijani B, Zahedi F. Ethical and religious aspects of gamete and embryo donation and legislation in Iran. J Relig Health. 2007;46(3):399-408.

30. Inhorn MC, Gürtin ZB. Infertility and assisted reproduction in the Muslim Middle East: social, religious, and resource considerations. FVV in ObGyn. 2012;MOnOGraph:24-9.

31. Peckham S, Hann A. Public health ethics and practice. UK: Policy Press; 2009.

32. Callahan D, Jennings B. Ethics and public health: forging a strong relationship. Am J Public Health. 2002;92(2):169-76. PMID:11818284

33. Boylan M. Public health policy and ethics. New York: Kluwer Academic Publishers; 2005.

34. Alkabba AF, Hussein GMA, Albar AA, Bahnassy AA, Qadi M. The major ethical challenges facing the public and healthcare providers in Saudi Arabia. J Family Community Med. 2012;19(1):1-6. doi:10.4103/2230-8229.94003.

35. Aramesh K. A brief history of biomedical research ethics in Iran: conflict of paradigms. Dev World Bioeth. 2015;15(2):107-12. doi:10.1111/dewb.12053 